\title{
Gas liquid chromatography for detection of bacteriuria: examination for volatile acidic and neutral compounds
}

\author{
ELAINE BARRETT, G. LYNAM, AND SHEILA TRUSTEY \\ From the Division of Hospital Infection, Clinical Research Centre and Northwick Park Hospital, \\ Harrow, Middlesex, HAl 3UJ, UK
}

SUMMARY Direct injection of clinically infected urines on porous-polymer columns was investigated to determine which microbial metabolites were consistently detectable, and whether their presence could be used as a reliable index of infection. Chromosorb 101 was found to be the most suitable porous polymer for the detection of microbial metabolites; greater sensitivity of detection was achieved by partial purification of the urine before injection. Acetic acid was the only compound found consistently and it enabled $10^{6}$ microorganisms per $\mathrm{ml}$ to be detected in urine. However, as urinary tract infection is diagnosed by the presence of $10^{5}$ organisms or more per $\mathrm{ml}$, our method is insufficiently sensitive for the detection of bacteriuria. Escherichia coli, Enterobacter cloacae, Klebsiella spp, Proteus spp, Stapyhlococcus albus, and Streptocococcus faecalis were detectable by our method but Pseudomonas aeruginosa and Candida albicans were not.

Screening of urine for the presence of significant numbers of microorganisms contributes considerably to the workload of a department of diagnostic microbiology. A diagnosis of urinary tract infection is indicated by a simple viable count revealing the presence of $>10^{5}$ microorganisms per $\mathrm{ml}$ of urine, and a report is sent after further tests for identification and antibiotic sensitivity of the causative agent. Because many specimens are received containing insignificant numbers of microorganisms, the viable count is time-consuming and expensive of materials and technician time. It would be valuable if a rapid screening procedure could be devised to select the few specimens requiring further work. A suitable method should be easily automated and sufficiently sensitive to detect $10^{4}$ microorganisms per $\mathrm{ml}$, thus ensuring reliable selection of all positive specimens.

Our approach was to use gas-liquid chromatography (GLC) to detect microbial metabolites in urine. The potential use of GLC as a diagnostic aid in clinical microbiology has been indicated by other workers, in particular, Mitruka et al. (1972), and it has also been demonstrated that the technique can be readily automated for the detection of microbial metabolites (Brooks et al., 1973). We considered

Received for publication 23 January 1978 that volatile acidic and neutral compounds of low molecular weight, such as the lower fatty acids and alcohols, would be among the main detectable substances produced in urine by the microorganisms responsible for urinary tract infection; these substances can be easily detected in culture media by injection of an aqueous solution on columns packed with porous polymers (Cecchini and O'Brien, 1968; Rogosa and Love, 1968; Yoshioka et al., 1969; Henkel, 1971).

\section{Material and methods}

GAS-LIQUID CHROMATOGRAPHY

A Pye series 104 gas chromatograph with heated dual flame-ionisation detectors was used. The instrument was operated isothermally as a singlechannel instrument with glass columns of $1.5 \mathrm{~m}$ length and $4 \mathrm{~mm}$ internal diameter.

\section{Column packings}

Chromosorb 105; Chromosorb 101; Poropak P; Poropak Q; Poropak N; Poropak T. All were 80-100 mesh (Phase Separations Ltd, Clwyd).

\section{Gases}

The carrier gas was nitrogen, at a flow rate of $50 \mathrm{ml}$ per minute. Hydrogen and compressed air were operated with optimised flow rates. 
Improvement of chromatographic technique

This was applied in all but the preliminary experiments. Ghosting was reduced to a minimal level, enabl ng reproducible results to be obtained by:

i $1 \mu$ l on-column injection and rigorous syringe cleaning;

ii treatment of column glass with dilute hydrochloric acid after cleaning;

iii use of Teflon wool for column plugs;

iv thorough washing of porous polymers with acetone, methanol, and water before packing.

We found the last procedure to be the most significant in limiting ghosting. Other workers have advocated the incorporation of formic acid vapour in the carrier gas for this purpose (Geddes and Gilmour, 1970; Ackman, 1972; Van Eenaeme et al., 1974). However, at the concentration required to limit ghosting, the use of fractionated formic acid to generate formic acid vapour so increased the noise and standing current on the detector that the use of the gas chromatograph was restricted to unacceptably high levels of attenuation.

MICROORGANISMS

All the microorganisms were isolated from patients with urinary tract infection. Candida albicans, Escherichia coli, Klebsiella spp, Pseudomonas aeruginosa, Proteus spp, Staphylococcus albus, and Streptococcus faecalis were obtained from the Department of Microbiology at Northwick Park Hospital, and Enterobacter cloacae from the Salmonella and Shigella Reference Laboratory, Colindale, London.

\section{URINE}

Clinical urine specimens were obtained from the Department of Microbiology at Northwick Park Hospital. They were considered to be infected when $10^{5}$ microorganisms per $\mathrm{ml}$ were present, as estimated by a standard-loop technique. Normal urine specimens were obtained from healthy laboratory staff.

'Cleaning up' of urine

Five millilitres of urine was treated before injection by removal of:

i cells and microorganisms by pressure filtration through a membrane filter, pore size $0.22 \mu \mathrm{m}$ (Millipore Corporation);

ii high-molecular-weight compounds such as proteins by pressure filtration through an ultrafiltration membrane (Millipore Corporation);

iii cations by shaking with cation-exchange resin AG 50W-X4 in the hydrogen form, 200-400 mesh (Bio-Rad Laboratories). This treatment also ensured the liberation of the acids as free acids at $\mathbf{p H} 1$.

\section{Concentration of urine}

Urines 'cleaned up', as described above, were concentrated 20 -fold by slow evaporation at $60^{\circ} \mathrm{C}$ under a stream of nitrogen. The acid components were preserved by prior conversion to their sodium salts with $10 \mathrm{~m}$ sodium hydroxide, and before injection the concentrates were acidified with $8 \mathrm{M}$ hydrochloric acid to liberate the free acids. Volatile neutral compounds would, however, have been driven off.

\section{VIABLE COUNTS}

Viable counts were performed by a modification of the method of Miles et al. (1938), in which 0.01-ml volumes were delivered from an automatic pipette.

\section{Results}

\section{INJECTION OF UNTREATED URINE}

Our first objective was to discover whether the simple procedure of injection, on a porous-polymer column, of urine infected with the commonest urinary tract pathogen, $E$. coli, could reveal the presence of enough metabolites to serve as an indicator of significant bacteriuria.

\section{Preliminary comparison of chromatograms of \\ infected and uninfected urines}

Eighty-six clinical urines infected with $E$. coli were chromatographed by injection of $3 \mu 1$ on a column of Chromosorb 105 . The only peak obtained consistently had a retention time $\left(R_{t}\right)$ of 7.5 minutes and a mean height of $29.3 \mathrm{~mm}$. The height of this peak above which a urine could be designated as 'infected' was determined by study of a control group of 37 uninfected clinical urines. These were chromatographed in the same way as the infected urines and gave a mean peak height of $3.4 \mathrm{~mm}$ with standard deviation of $2.3 \mathrm{~mm}$. The threshold value for the peak height was set, 2.5 standard deviations above the mean at $11 \mathrm{~mm}$.

A comparison of the peak heights of the uninfected and infected urines is shown in Fig. 1; with the threshold value for 'infection' set at $11 \mathrm{~mm}$, only $3 \%$ of uninfected urines were recorded as false positive but $36 \%$ of infected urines were recorded as false negative.

\section{Relationship of height of 7.5-minute peak to viable count of E. coli}

The viable count was correlated with the height of the $7.5 R_{t}$ peak for 29 clinical urines infected with $E$. coli and 35 experimentally infected urines, as shown in Table 1 . No urine containing less than $10^{7} \mathrm{E}$. coli per $\mathrm{ml}$ produced a significantly raised peak; but some urines with high viable counts failed to produce significantly raised peaks. 

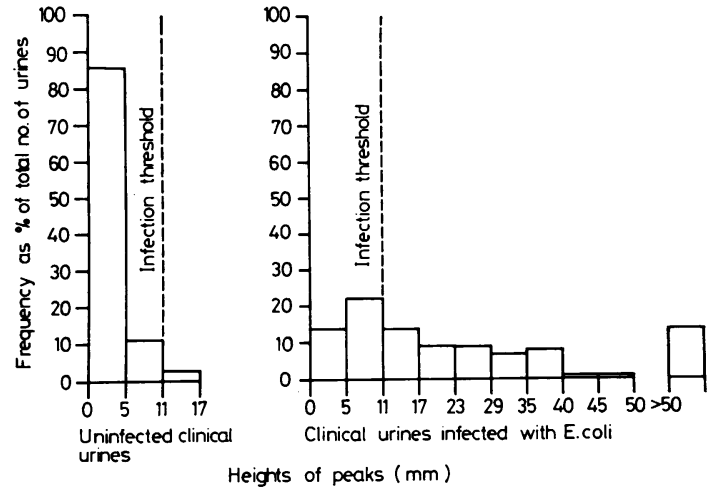

Fig. 1 Height of $7.5 R_{t}$ peak from 37 uninfected clinical urines and 86 clinical urines infected with E. coli $>10^{5}$ per ml. Column packing-Chromosorb 105; oven temperature $190^{\circ} \mathrm{C}$; detector-oven temperature $250^{\circ} \mathrm{C}$; injection-port heater temperature $220^{\circ} \mathrm{C}$; injection volume $3 \mu \mathrm{l}$; attentuation $2 \times 10^{-10}$.

Table 1 Relationship of $7 \cdot 5 R_{t}$ peak height to $\mathrm{E}$. coli count in urine

\begin{tabular}{lll}
\hline $\begin{array}{l}\text { Viable count } \\
\text { (cells per } \mathrm{ml})\end{array}$ & \multicolumn{2}{c}{$\begin{array}{l}\text { Number of urines giving peak height } \\
>11 \mathrm{~mm} / \text { number tested }\end{array}$} \\
\cline { 2 - 3 } & Clinical & $\begin{array}{l}\text { Experimentally } \\
\text { infected normal }\end{array}$ \\
\hline $10^{4}$ & $0 / 2$ & $\mathrm{NT}$ \\
$10^{5}$ & $0 / 2$ & $0 / 2$ \\
$10^{8}$ & $0 / 6$ & $0 / 10$ \\
$10^{7}$ & $9 / 12$ & $9 / 16$ \\
$10^{8}$ & $5 / 7$ & $7 / 7$ \\
\hline
\end{tabular}

NT $=$ not tested

Relationship of height of 7.5-minute peak to concentration of urine

Osmolality was used as a relative measure of concentration. For 19 clinical urines infected with $>10^{7} E$. coli per $\mathrm{ml}$, the osmolality was correlated with the height of the $7.5 R_{t}$ peak produced, as shown in Table 2. All the concentrated urines produced significantly raised peaks whereas more than half of the dilute urines failed to do so.

TESTING OF 'CLEANED UP' URINE

Although the technical procedure was essentially simple, problems were encountered: the phenomenon of 'ghosting' - the appearance of a peak related to a previous injection rather than the current injectiongave rise to spurious results; and charred deposits rapidly accumulated at the injection site, causing column deterioration. We thought that treatment
Table 2 Relationship of $7.5 R_{t}$ peak height produced by urine infected with $10^{7} \mathrm{E}$. coli per ml to dilution of urine; osmolality was used as a relative measure of dilution

\begin{tabular}{ll}
\hline $\begin{array}{l}\text { Osmolality } \\
(\text { mosm } / \mathrm{kg})\end{array}$ & $\begin{array}{l}\text { Number of urines giving peak height } \\
>11 \mathrm{~mm} / \text { number tested }\end{array}$ \\
\hline $100-199$ & $1 / 2$ \\
$200-299$ & $1 / 2$ \\
$300-399$ & $0 / 2$ \\
$400-499$ & $4 / 5$ \\
$500-599$ & $3 / 3$ \\
$600-699$ & $2 / 2$ \\
700 and over & $3 / 3$ \\
\hline
\end{tabular}

of the urine to remove non-metabolites before injection and general improvement of chromatographic technique would improve column sensitivity and might enable us to detect metabolites other than that associated with the $7.5 R_{t}$ peak. This was done as described in Methods.

Porous polymers other than Chromosorb 105 were also tested, as described below, and other microorganisms responsible for urinary tract infection were investigated in addition to $E$. coli, for example, C. albicans, Enterobacter cloacae, Klebsiella spp, Ps. aeruginosa, Proteus spp, Staph. albus, and Str. faecalis.

Choice of most suitable porous polymer for detection of bacterial metabolites in urine

A culture in the same normal urine was prepared for each of the main species of microorganisms responsible for urinary tract infection. After treatment, as described above, each culture and a control uninoculated urine were injected on columns of Poropak Q, N, T, and Chromosorb 101 and 105. The chromatographic profiles produced by the cultures were compared with those produced by the control. Differences between culture profiles and the control profile were observed only when either Chromosorb 101 or Poropak P was used. When the injections on Chromosorb 101 and Poropak $P$ were repeated with optimum operating conditions for each polymer, the results for each polymer were the same; the culture profiles showed an increase in peak height over the control profile for one or more of three peaks. Chromosorb 101 was selected for further study.

\section{Consistency of metabolite production in different urines}

Two cultures of $E$. coli in two different normal urines were prepared in addition to the urine previously used, and the same procedure was used to produce two more sets of chromatographic profiles from Chromosorb 101. Only one of the three raised 

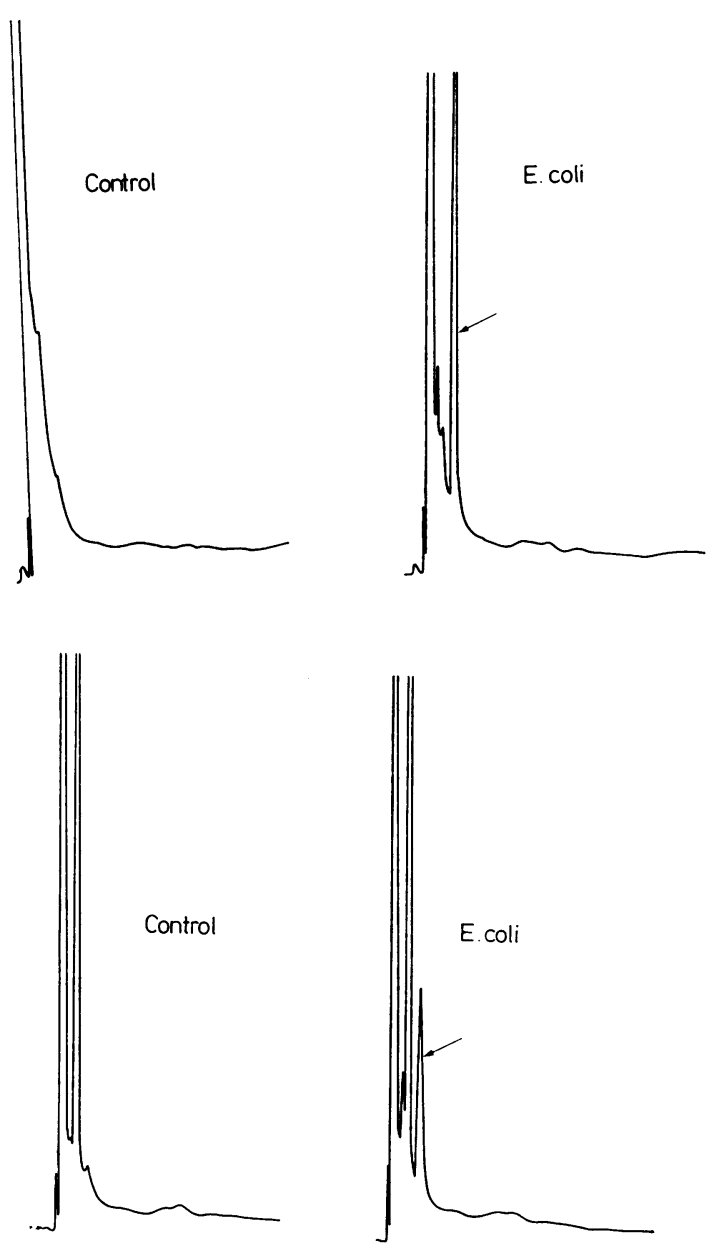

Fig. 2 Chromatograms from 'purified' preparations of two normal urines before and after incubation with $\mathrm{E}$. coli. Arrow indicates peak showing a large rise after culture of each urine. Column packing -

Chromosorb 101; oven temperature $185^{\circ} \mathrm{C}$; detectoroven temperature $230^{\circ} \mathrm{C}$; on-column injection volume $0.5 \mu \mathrm{l}$; attentuation $1 \times 10^{-10}$.

peaks that had appeared in the culture profile of the original urine showed a large consistent rise for all three urines; we referred to this as the infection peak'. The culture profiles obtained from two urines before and after culture are shown in Figure 2.

The same result was obtained for cultures of Enterobacter cloacae, Klebsiella spp, Proteus spp, Staph. albus, and Str. faecalis, but there was no consistent rise in any peak from $C$. albicans or Ps. aeruginosa.
Ability of Chromosorb 101 to detect likely microbial metabolites

A series of volatile acidic and neutral compounds likely to be produced as metabolites by the types of organisms responsible for urinary tract infection was prepared in urine, and the minimum quantities detectable by injection on Chromosorb 101, after the treatment procedure described above, were measured. The results are shown in Table 3. nPentanol was then selected for use as an internal standard, and the relative retention times of the compounds were subsequently determined in relation to it.

\section{Identity of infection peak}

The internal standard, n-pentanol, was added to the urines that had been cultured with $E$. coli, and they were re-chromatographed to determine the relative retention times of the infection peak. The value obtained was $0 \cdot 333$. Reference to Table 3 shows that, of the compounds tested, the only likely microbial metabolite with the same relative retention time was acetic acid.

The metabolite responsible for the infection peak was identified with a Varian Model MAT112 Mass Spectrometer. It gave the same ratio of the same fragmentations as acetic acid.

Comparison of areas of acetic-acid peaks in chromatograms from clinically infected and uninfected urines

The relative areas of the acetic-acid peaks from 43 clinical urines infected with one or more species of the microorganisms responsible for urinary tract infection after chromatography on Chromosorb 101 were compared with those produced by a control group of 51 uninfected clinical urines.

After addition of $326 \mathrm{ng}$ of the n-pentanol internal standard to $5 \mathrm{ml}$ of urine, the chromatograms were obtained as described above for cultures of normal urine, and the areas of the acetic-acid peaks were expressed as a percentage of the area of the internal standard. The mean relative peak area of the control group was $1.66 \%$ with standard deviation $1.30 \%$. As previously where the heights of the $7.5 R_{t}$ peak produced by urines infected with $E$. coli were considered, the threshold value above which a urine could be designated as 'infected' was set 2.5 standard deviations above the mean. This gave a threshold for relative peak area of $4.9 \%$ of the n-pentanol standard.

The comparison of the relative peak areas for the infected and uninfected groups is illustrated in Figure 3. The results are similar to those for peak height (Fig. 1) in that only $2 \%$ of uninfected urines produced relative areas above the threshold value, 
Table 3 Amounts of likely microbial metabolites required to produce $10 \%$ full-scale deflection (FSD) when injected in urinary solution on Chromosorb 101, and relative retention time

\begin{tabular}{lcc}
\hline Compound & $\begin{array}{c}\text { Quantity required to produce } \\
10 \% \text { FSD (ng) }\end{array}$ & $\begin{array}{c}\text { Retention time relative to } \\
n-p e n t a n o l\end{array}$ \\
\hline Acetic acid (ethanoic acid) & $48 \cdot 154$ & $0 \cdot 329$ \\
Propionic acid (propanoic acid) & $53 \cdot 793$ & $0 \cdot 553$ \\
Butyric acid (butan-1-oic acid) & $74 \cdot 524$ & $1 \cdot 000$ \\
Iso-butyric acid (butan-2-oic acid) & $36 \cdot 706$ & $0 \cdot 794$ \\
Valeric acid (pentan-1-oic acid) & $121 \cdot 429$ & $1 \cdot 713$ \\
Caproic acid (hexan-1-oic acid) & $194 \cdot 118$ & $3 \cdot 102$ \\
Ethanol & $7 \cdot 647$ & $0 \cdot 195$ \\
Propanol (propan-1-ol) & $9 \cdot 630$ & $0 \cdot 313$ \\
Isopropanol (propan-2-ol) & $7 \cdot 647$ & $0 \cdot 228$ \\
Butanol (butan-1-ol) & $31 \cdot 200$ & $0 \cdot 542$ \\
n-Pentanol (pentan-1-ol) & $138 \cdot 356$ & $1 \cdot 000$ \\
Pentan-3-one & $22 \cdot 429$ & $0 \cdot 668$ \\
Acetoin (3-hydroxybutan-2-one) & $127 \cdot 632$ & $0 \cdot 863$ \\
Propane-1,3-diol & $102 \cdot 459$ & $1 \cdot 520$ \\
Butan-2,3-diol & $51 \cdot 148$ & $1 \cdot 249$ \\
\hline
\end{tabular}

IUPAC nomenclature in parentheses

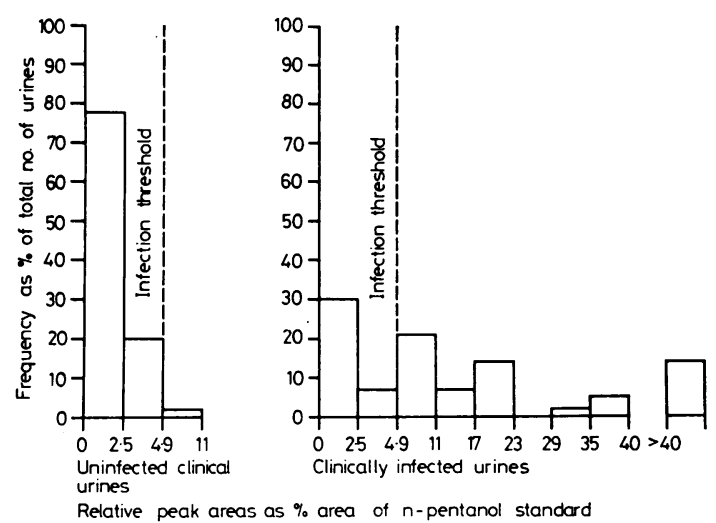

Fig. 3 Relative area of acetic-acid peak from 51 uninfected clinical urines and 43 clinical urines infected with $>10^{5}$ per $\mathrm{ml}$ of one or more of eight species of microorganism mentioned in text. Chromatographic conditions as indicated for Figure 1.

but $37 \%$ of infected urines produced relative peak areas below this value.

\section{Relationship between area of acetic-acid peak and} viable count

The 43 clinically infected urines for which the relative peak area of the acetic-acid peak had been determined, as described above, were considered in four groups: $E$. coli infection, $P$ s. aeruginosa infection, Proteus infections, and mixed infections. For each group the viable count was correlated with the relative area of the acetic-acid peak, as shown in Table 4. All the urines infected with Ps. aeruginosa produced relative peak areas below the threshold for 'infection' $(4.9 \%)$, and urines infected with other organisms required the presence of at least $10^{6}$ microorganisms per $\mathrm{ml}$ to produce relative peak areas above the threshold.

\section{TESTING OF CONCENTRATED URINE}

It seemed possible that acidic and neutral compounds other than acetic acid were not demonstrable in infected urine because their concentration was lower than the limit of detection on Chromosorb 101. Concentration of the urine might therefore enable them to be detected.

\section{Detection of microbial metabolites in concentrated} urine by Chromosorb 101

The loss of acetic acid during 20 -fold concentration by the procedure described in Methods was determined for a standard solution and was found to be insignificant.

Table 4 Relationship of acetic-acid peak area to number of microorganisms in urine

\begin{tabular}{llllll}
\hline & $\begin{array}{l}\text { E. coli } \\
\text { (clinical) }\end{array}$ & $\begin{array}{l}\text { E. coli } \\
\text { (experimentally } \\
\text { infected) }\end{array}$ & $\begin{array}{l}\text { Ps. aeruginosa } \\
\text { (clinical) }\end{array}$ & $\begin{array}{l}\text { Proteus spp } \\
\text { (clinical) }\end{array}$ & $\begin{array}{l}\text { Mixed } \\
\text { (clinical) }\end{array}$ \\
\hline $10^{4}$ & $0 / 1$ & $0 / 2$ & NT & NT & NT \\
$10^{5}$ & $0 / 4$ & $0 / 4$ & NT & $1 / 1$ & $0 / 5$ \\
$10^{8}$ & $5 / 6$ & $2 / 4$ & $0 / 2$ & $2 / 3$ & $6 / 6$ \\
$10^{7}$ & $11 / 11$ & $2 / 3$ & & & $3 / 3$ \\
\hline
\end{tabular}

$\mathrm{NT}=$ not tested 
Comparison of the chromatographic profiles of concentrates of $E$. coli culture with those of the controls revealed no metabolites other than the acetic acid detectable in unconcentrated urine. The profiles obtained for one urinary concentrate are presented in Figure 4. The same finding was obtained for concentrated cultures of the other microorganisms responsible for urinary tract infection. Volatile acid metabolites other than acetic acid were not produced in detectable amounts.

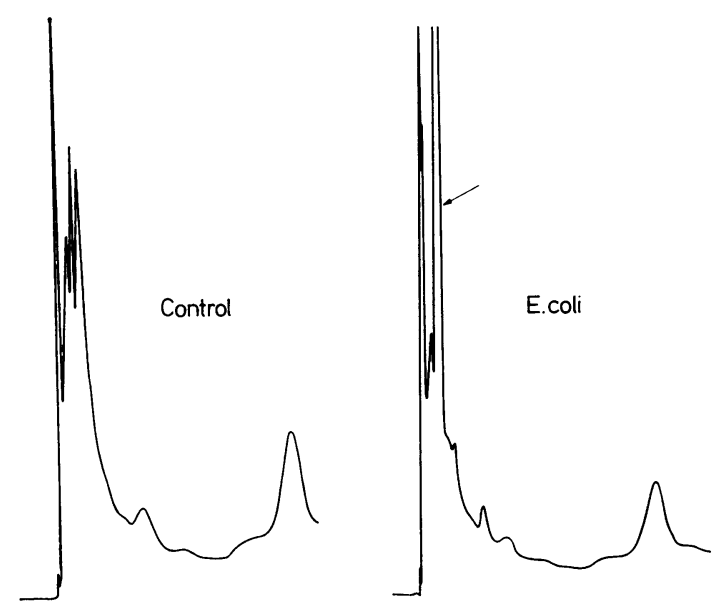

Fig. 4 Chromatograms from concentrated preparations of normal urine before and after incubation with E. coli. Arrow indicates peak corresponding to acetic acid and showing a large rise after culture of each urine. Chromatographic conditions as indicated for Figure 2.

\section{Discussion}

The simple procedure of injecting untreated urine on a porous polymer column, Chromosorb 105, provided a rapid method of detecting infection in some urines by recording a raised acetic-acid peak. Too many false negatives occurred, however, for the method to be useful as a screening test for bacteriuria. The insensitivity of the method-detection of only $10^{7}$ organisms per $\mathrm{ml}$ whereas $10^{5}$ organisms per $\mathrm{ml}$ is the accepted criterion of significant bacteriuria-and recording of false negatives in dilute urine with high bacterial counts together with charring of the crude material introduced into the gas chromatograph contributed to the failure of the procedure.

Detection of low urinary concentrations of likely volatile acidic and neutral microbial metabolites was achieved by selection of a more suitable porous polymer, Chromosorb 101, improved chromato- graphic procedure, and the use of 'cleaned-up' urine; but when it was used to analyse urines infected with each of the principal microorganisms responsible for urinary tract infection, the only microbial metabolite consistently detected was acetic acid. This was detectable only when at least $10^{6}$ microorganisms per $\mathrm{ml}$ were present, and was not produced by all the species tested, for example, pseudomonas and candida. Concentration of the urine by evaporation did not reveal the presence of metabolites other than acetic acid.

We have found that the use of solvent extraction to obtain and concentrate acidic and neutral metabolites, although simple, was less effective than the direct injection of aqueous solutions, because of the poor partition characteristics of the volatile acids in organic solvents.

It must be concluded that the microorganisms responsible for urinary tract infection liberate insufficient quantities of volatile small acidic and neutral molecules into the urine to serve as a reliable index of infection. Basic or non-volatile compounds may be more suitable indices, and work on their detection is now in progress.

We thank Mr M. D. Chu for the mass-spectrometry identification of the acetic-acid peak, and Mrs Pamela Jackson and Mr P. Reed for technical assistance. The figures were produced with the help of the Department of Medical Illustration at the Clinical Research Centre.

\section{References}

Ackman, R. G. (1972). Porous polymer bead packings and formic acid vapor in the GLC of volatile free fatty acids. Journal of Chromatographic Science, 10, 560565.

Brooks, J. B., Alley, C. C., Weaver, J. W., Green, V. E., and Harkness, A. M. (1973). Practical methods for derivatizing and analysing bacterial metabolites with a modified automatic injector and gas chromatograph. Analytical Chemistry, 45, 2083-2087.

Cecchini, G. L., and O'Brien, R. T. (1968). Detection of Escherichia coli by gas chromatography. Journal of Bacteriology, 95, 1205-1206.

Geddes, D. A. M., and Gilmour, M. N. (1970). The control of ghosting, a major source of error in gas liquid chromatographic determinations of $\mathrm{C}_{2}-\mathrm{C}_{5}$ acids. Journal of Chromatographic Science, 8, 394-397.

Henkel, H. G. (1971). Gas-chromatographic analysis of low boiling fatty acids in biological media. Journal of Chromatography, 58, 201-207.

Miles, A. A., Misra, S. S., and Irwin, J. O. (1938). The estimation of the bacteriocidal power of the blood. Journal of Hygiene, 38, 732-749.

Mitruka, B. M., Kundargi, R. S., and Jonas, A. M. (1972). Gas chromatography for rapid differentiation of 
bacterial infection in man. Medical Research Engineering, 11, 7-11.

Rogosa, M., and Love, L. L. (1968). Direct quantitative gas chromatographic separation of $\mathrm{C}_{2}-\mathrm{C}_{6}$ fatty acids, methanol, and ethyl alcohol in aqueous microbial fermentation media. Applied Microbiology, 16, 285-290.

Van Eenaeme, C., Bienfait, J. M., Lambot, O., and Pondant, A. (1974). Studies on ghosting, an important source of error in the quantitative estimation of free volatile fatty acids by GLC 1 . Occurrence of ghosting and factors influencing it. Journal of Chromatographic Science, 12, 398-403.

Yoshioka, M., Kitamura, M., and Tamura, Z. (1969). Rapid gas-chromatographic analysis of microbial volatile metabolites. Japanese Journal of Microbiology, 13, 87-93.

Requests for reprints to: G. Lynam, Division of Hospital Infection, Clinical Research Centre, Watford Road, Harrow, Middlesex, HA1 3UJ, UK. 